Fernández Enríquez, A., Arcila Garrido, M., García Sanabria, J. (2019): "Metodología de valoración de impacto visual. Aplicación en la playa de el Palmar de Vejer (Cádiz).”, GeoFocus (Artículos), no 23, p. 141-162. ISSN: 15785157 http://dx.doi.org/10.21138/GF.624

\title{
METODOLOGÍA DE VALORACIÓN DE IMPACTO VISUAL. APLICACIÓN EN LA PLAYA DE EL PALMAR DE VEJER (CÁDIZ)
}

\author{
ALFREDO FERNÁNDEZ ENRÍQUEZ, MANUEL ARCILA GARRIDO, JAVIER GARCÍA \\ SANABRIA \\ Departamento de Historia, Geografía y Filosofía. Área de Análisis Geográfico Regional. \\ Universidad de Cádiz. \\ Avenida Gómez Ulla s/n, 11003 Cádiz, España \\ alfredo.fernandez@uca.es, manuel.arcila@uca.es, javier.sanabria@uca.es
}

\section{RESUMEN}

El paisaje, expresión sensible del entorno, puede ser analizado desglosando factores escénicos y elementos del paisaje. Este artículo presenta una nueva metodología de valoración de la calidad visual del paisaje aplicada a una actuación urbanística costera en Andalucía, un Plan Parcial en la playa de El Palmar de Vejer (Cádiz). Cuantificando forma, línea, color, textura y escala se mide la calidad del paisaje antes y después de la construcción prevista, y se proponen medidas correctoras del impacto visual.

Palabras clave: impacto visual, paisaje, técnicas cuantitativas.

\section{A METHODOLOGY TO EVALUATE VISUAL IMPACT. APPLICATION TO THE BEACH OF EL PALMAR DE VEJER (CÁDIZ).}

\section{ABSTRACT}

Landscape is sensitive expression of our environment, whose analysis shows different elements and scenic factors. This paper is focused on a new evaluation methodology for visual quality of landscape and visual impact, applied to a proposal of new buildings on the beach of El Palmar de Vejer (Cádiz), in the Spanish region of Andalusia. Landscape quality is measured before and after the planned construction, by quantifying shape, line, color, texture and scale. Corrective measures are proposed to prevent visual impact.

Key words: visual impact, landscape, quantitative techniques. 
Fernández Enríquez, A., Arcila Garrido, M., García Sanabria, J. (2019): "Metodología de valoración de impacto visual. Aplicación en la playa de el Palmar de Vejer (Cádiz).”, GeoFocus (Artículos), no 23, p. 141-162. ISSN: 15785157 http://dx.doi.org/10.21138/GF.624

\section{Introducción}

El creciente interés por el recurso Paisaje ha inducido la proliferación de metodologías de evaluación de la calidad visual y del impacto de actuaciones en diversos contextos. En 2003 se tramitó un controvertido Plan Parcial ${ }^{1}$ con edificación hotelera en el entorno de la playa de El Palmar de Vejer, en la provincia de Cádiz, hoy día aún sin ejecutar como consecuencia del estallido de la burbuja inmobiliaria. El correspondiente estudio de impacto ambiental ${ }^{2}$ incluyó un estudio de impacto visual que cuantificó el impacto visual previsible para establecer las necesarias medidas correctoras.

La solidez, originalidad y ventajas de la metodología propuesta en ese estudio pueden apreciarse en el contexto de la evolución del estudio del paisaje, de la que a continuación se presentará una sinopsis. Después se presentará el caso de estudio, extrayendo los aspectos más originales de la metodología utilizada y se ilustrará su aplicación en el EIA de la playa de El Palmar. Al final se discutirán las ventajas que presenta éste método a la luz de la experiencia reciente y se propondrán conclusiones a modo de resumen.

\section{Marco teórico}

\subsection{Primeras aproximaciones al paisaje como recurso natural.}

F.L. Olmsted, diseñador de Central Park en 1858, concibió la arquitectura del paisaje para poner en contacto al público con el paisaje conservando las características del mismo y proporcionando las comodidades y servicios pertinentes. Olmsted consideraba la belleza sustento de la moral y felicidad humana. Junto a destacados naturalistas promovió la protección de Yosemite Valley, declarado por Lincoln paisaje pintoresco en 1865. Desde la década de 1960 la planificación paisajística consiste en localizar y unificar diferentes usos del suelo basándose en los conocimientos técnicos sobre la fisiología del paisaje y en la aprehensión estética de su exterioridad (Laurie, 1983).

Considerar el paisaje como la apariencia escénica de la tierra, y por tanto un recurso natural en sí mismo, implica que sus características pueden ser descritas objetivamente aplicando conceptos extraídos de los campos de las artes, el diseño, la ecología y la gestión de recursos. Su aplicación puede combinar dos grandes grupos de métodos (trabajo técnico individual de un experto, o consulta al público mediante encuestas) y enfoques (el ortogonal, propio de la fotografía aérea vertical, o el oblicuo propio de la fotografía convencional).

El método experto considera la belleza escénica inherente al paisaje y susceptible de ser desagregada en componentes (geomorfología, hidrología, vegetación...) cuyas características pueden ser categorizadas por un experto para establecer jerarquías aplicando escalas de valores socialmente aceptables.

Alternativamente, el método de las preferencias del público utiliza encuestas en las que los participantes califican fotografías para establecer la escala social de valores estéticos. Ambos métodos pueden combinarse y someter los resultados a análisis estadístico.

\footnotetext{
${ }^{1}$ Aprobación definitiva el 10/05/2007. BOP 174, de 10/09/2010 disponible en: http://ws041.juntadeandalucia.es/medioambiente/situadifusion/pages/descargaDocumentos.jsf?doc=9 8330

2 EsIA realizado por IBERMAD Medio Ambiente y Desarrollo S.L. (2003), disponible en el registro autonómico de instrumentos de planeamiento y en el municipal de Vejer de la Frontera.
} 
Fernández Enríquez, A., Arcila Garrido, M., García Sanabria, J. (2019): "Metodología de valoración de impacto visual. Aplicación en la playa de el Palmar de Vejer (Cádiz).”, GeoFocus (Artículos), nº 23, p. 141-162. ISSN: 15785157 http://dx.doi.org/10.21138/GF.624

En cuanto al enfoque, a una escala de análisis territorial (municipal, regional, ...) la herramienta más característica es la fotografía aérea, que denominaremos vertical por contraposición al enfoque horizontal, más adecuado a una escala de proyecto donde predomina el análisis escénico de fotografía paisajística convencional para aprehender las características estéticas del lugar a escala humana.

El enfoque vertical es utilizado en evaluación de impacto ambiental. Previa definición de unidades ambientales homogéneas, la superposición de las actuaciones previstas permite obtener sectores de impacto. Del mismo modo puede obtenerse la calidad visual del territorio antes de una actuación y los sectores de impacto visual después de la actuación.

Por contraposición, el enfoque horizontal es utilizado a escala de detalle para analizar el impacto de proyectos concretos y su difusión por el entorno de un lugar concreto. El paradigma es la matriz de impacto ambiental, núcleo del método vector-factor (Leopold et al., 1971). Leopold fue también pionero del análisis visual. Utilizando la fotografía paisajística, abrió camino a los métodos oficializados por diversas agencias gubernamentales estadounidenses; de gestión forestal, de infraestructuras y otras.

A grandes rasgos, la evolución metodológica en EE.UU. viene marcada por los siguientes hitos.

- Identificación de variables cuantificables en la observación del paisaje; forma, escala, color, distancia, posición del observador y secuencia de la observación (Litton, 1968).

- Evaluación cuantitativa de la singularidad, atractivo visual y naturalidad de doce ríos utilizando una matriz de valoración con 46 criterios; características físicas y biológicas, y factores de interés humano (Leopold, 1969).

- Análisis geométrico sobre fotografía de la distribución de agua, cielo, vegetación y novegetación, en primer plano, plano medio y fondo. Se contrasta con las preferencias del público y los resultados se someten a tratamiento estadístico (Shafer, 1969).

- Utilización de mapas mallados para para describir la calidad visual de cada celda y medir el impacto visual, obviando la interacción entre celdas (Arthur, 1977).

- Consolidación de los paradigmas psicofísico, cognitivo y experiencial (Zube, et. al, 1982).

- Contraste del enfoque experto vertical con las preferencias del público. Identificación sobre fotografía aérea de colinas arboladas periurbanas, cuya eventual urbanización es percibida como impacto visual por el público (Schroeder, 1988).

- Análisis experto de cuencas visuales y usos del suelo para obtener categorías cuyo grado de naturalidad es establecido por la población valorando fotografías paisajísticas que cubren un periodo de 20 años en Cape Cod. El análisis estadístico de los resultados proporciona la métrica espacial del paisaje y permite predecir su evolución (Palmer, 2004).

\subsection{La formalización administrativa}

La Countryside Act "de conservación de la belleza natural y la amenidad del campo" fue promulgada en 1968 en Reino Unido, y en 1969 en EE.UU. lo fue la National Environmental Policy Act, que pretende "garantizar un entorno seguro, saludable, productivo y agradable a nivel estético y cultural para todos los estadounidenses" (Zube, et. al, 1982).

Por imperativo legal se impulsan desde entonces diversos mecanismos sectoriales de gestión del recurso paisaje, aplicados sobre todo a paisajes excepcionales, y muy similares entre sí, utilizando el método experto, el uso de simulaciones visuales y midiendo el impacto visual como la diferencia entre la calidad visual de un paisaje antes y después de la ejecución de un proyecto. 
Fernández Enríquez, A., Arcila Garrido, M., García Sanabria, J. (2019): "Metodología de valoración de impacto visual. Aplicación en la playa de el Palmar de Vejer (Cádiz).”, GeoFocus (Artículos), nº 23, p. 141-162. ISSN: 15785157 http://dx.doi.org/10.21138/GF.624

Todos los procedimientos relacionados a continuación siguen siendo de aplicación en las esferas de competencia da cada administración, sin más convergencias metodológicas que la recomendación de buenas prácticas extraídas de la experiencia colectiva (Churchward et al., 2013).

- SMS (Scenary Management System) y SBEM (Scenic Beauty Estimation Method). Evaluación de la calidad visual analizando geomorfología, forma, línea, textura, color y sensibilidad para el usuario (servicio forestal del departamento de agricultura).

- Visual Impact Assesment. Diseño escénico de infraestructuras viarias mediante análisis detallado de los componentes del paisaje (forma, línea, textura, color y escala) (administración federal de autopistas).

- Visual Resources Management. Análisis de color, geometría (forma, línea y textura), geomorfología, vegetación, agua, escenario circundante, variedad, rareza y carácter distintivo en espacios naturales protegidos, antes y después de la simulación de un proyecto (oficina de gestión de suelos del departamento de interior).

- Visual Resources Assessment Procedure (cuerpo de ingenieros del ejército).

En España, el Convenio Europeo del Paisaje entró en vigor en $2008^{3}$, promoviendo el inventario y clasificación integral del paisaje y el establecimiento de objetivos de calidad paisajística, que han de guiar las políticas públicas como factor integrador en ordenación del territorio.

En Cataluña, la Ley 8/2005, de Protección, Gestión y Ordenación del Paisaje de Cataluña crea el Catálogo de Paisaje. Su posterior desarrollo por el Decreto 343/2006 establece la obligatoriedad de redactar Estudios de Impacto e Integración Paisajística (EIIP) para esclarecer las consecuencias que tiene sobre el paisaje la ejecución de actuaciones, proyectos de obras o actividades y exponer los criterios adoptados para su integración (Busquets y Muñoz, 2010).

Los EIIP analizan elementos dominantes (puntos, líneas, formas y volúmenes), cromatismo (colores, reflexión, estacionalidad cromática), texturas (grano, contraste, disposición), pautas formales (mosaico, continuidades, rupturas) y fragilidad, o capacidad de absorber impactos.

En Galicia se aplican desde 2008 EIIP incluyendo todos los impactos sensoriales; visuales, sonoros y sensitivos en general. Entre los impactos visuales se incluyen las transformaciones de patrones formales y/o compositivos: (forma, textura, escala) dentro de las distintas escenas (Borobio, 2012).

En Valencia, también desde 2008, los EIIP orientan el desarrollo urbanístico y territorial, contribuyendo a zonificar el SNU para preservar los elementos estructurales que definen el carácter del paisaje y la identidad de cada lugar (Muñoz Criado, 2012).

La Estrategia de Paisaje de Andalucía (Junta de Andalucía, 2012) persigue integrar el paisaje en todas las políticas autonómicas con carácter transversal, y alcanzar la gobernanza paisajística mediante un pacto por el paisaje. En Andalucía la protección del paisaje se incluye en 18 leyes, tres decretos y más de 250 normas de menor rango. Destacan el Estatuto de Autonomía, la Ley 1/1994, de Ordenación del territorio, y el Decreto 292/1995 de aprobación

\footnotetext{
${ }^{3}$ Convenio Europeo del Paisaje. BOE 31, de 5 de febrero de 2008. Disponible en: http://www.magrama.gob.es/en/desarrollo-rural/temas/desarrollo-territorial/09047122800d2b47_tcm1125185.pdf
} 
Fernández Enríquez, A., Arcila Garrido, M., García Sanabria, J. (2019): "Metodología de valoración de impacto visual. Aplicación en la playa de el Palmar de Vejer (Cádiz).”, GeoFocus (Artículos), nº 23, p. 141-162. ISSN: 15785157 http://dx.doi.org/10.21138/GF.624

del Reglamento de Evaluación de Impacto Ambiental, donde se incluye el paisaje entre las características a describir de las unidades ambientalmente homogéneas. Además, la Red de Información Ambiental de Andalucía (REDIAM) proporciona exhaustiva información sobre el paisaje andaluz.

\subsection{Nuevas metodologías recientes.}

Una breve síntesis puede incluir las siguientes aportaciones metodológicas recientes, entre las que destaca el impacto alcanzado por el denominado método español aplicado a parques eólicos. La mayoría aplica el método experto con el enfoque horizontal, complementado en algunos casos con el método de las preferencias del público y su análisis estadístico.

- Cartografía de calidad de paisajes agroforestales mediante valoración cuantitativa de 16 atributos de tres tipos; físicos, psicológicos y estéticos (formas, colores y texturas). Valorados en escalas cualitativas, se les asigna un valor cuantitativo, de modo directo o en función de otra variable dentro del mismo parámetro. La cuantificación de cada valor se ha establecido a través del manejo estadístico de datos provenientes de encuestas de preferencia (Rúiz Sánchez et al., 2006).

- Relación de las preferencias del público con los elementos y atributos visuales del paisaje del medio rural andaluz (Arriaza et al., 2004)

- Método español de predicción del impacto visual de parques eólicos, considerando el emplazamiento de los aerogeneradores y de las viviendas de la población afectada (Hurtado et al., 2004).

- Cartografía de calidad paisajística en los Montes de Toledo (Otero et al., 2007).

- Metodologías de carácter cualitativo para el estudio de conjuntos históricos (Campos, 2006)

- Impacto visual de edificaciones aisladas en el medio rural mediante contraste con el contexto de color (matiz, saturación, luminosidad), textura (regularidad, densidad, tamaño de grano), líneas (nitidez, complejidad, orientación) y formas (geometría, complejidad, orientación). (García et al., 2003, 2006 y 2010).

- Análisis de correlación estadística entre las conclusiones elaboradas por expertos, que desagregan y valoran componentes del paisaje, y las preferencias del público, que evalúa el paisaje en su totalidad, sin valorar sus componentes individuales (Torres, 2010).

- Integración de las preferencias del público mediante análisis semántico diferencial del paisaje rural (en términos de agrado, complejidad, coherencia...) validado por coeficientes de correlación (Cloquell-Ballester et al., 2011).

- Método español modificado para mejorar el cálculo de los coeficientes y la participación pública en evaluación del impacto visual de parques eólicos (Manchado et al., 2015)

- Selección subjetiva por expertos de paisajes visualmente uniformes donde se miden atributos, se definen criterios de consulta a la población y se cuantifican de forma objetiva líneas, formas, colores, textura, composición espacial y escala (Zubelzu y Hernández, 2015).

- Enfoque vertical en entorno web para facilitar una evaluación multi-criterio y colaborativa de la idoneidad de emplazamientos rurales para nueva edificación (Jeong et al., 2014; Jeong y García, 2016).

Tanto el método experto como los basados en las preferencias del público presentan ventajas y desventajas. El análisis de las preferencias del público es considerado costoso y fácilmente manipulable. Del método experto ha sido criticada la subjetividad en la selección de 
Fernández Enríquez, A., Arcila Garrido, M., García Sanabria, J. (2019): "Metodología de valoración de impacto visual. Aplicación en la playa de el Palmar de Vejer (Cádiz).", GeoFocus (Artículos), nº 23, p. 141-162. ISSN: 15785157 http://dx.doi.org/10.21138/GF.624

elementos y escalas de valoración, destacando que distintos expertos producen distintas valoraciones de los mismos paisajes, y la valoración del paisaje natural por encima del antropizado en todos los casos, que se ha demostrado incierta (Churchward et al., 2013).

\section{El caso del litoral andaluz}

En el litoral cada vez son más reducidos los espacios libres de edificación. En 1987, el $35,75 \%$ de los 500 metros adyacentes al litoral gaditano eran artificiales, y en 2011 se llegó al 50,28\% (Estévez et al., 2016).

El impacto visual de la nueva edificación costera no puede evaluarse aplicando criterios de contraste con el entorno como los utilizados en minería, carreteras, medio rural o parques eólicos, pues en el litoral escasean cada vez más los entornos no modificados, antropización que relativiza los nuevos impactos.

La concreción numérica de determinados hechos es una poderosa herramienta descriptiva que puede contribuir decisivamente al control de procesos graduales, como es la edificación en las periferias urbanas. Estos espacios presentan grandes dificultades en la valoración de su calidad visual y del impacto de actuaciones concretas. Sólo la cuantificación de la calidad y fragilidad visual de un paisaje concreto antes y después de una actuación urbanística permite describir objetivamente el impacto visual y las medidas correctoras necesarias, en su caso.

Un ejemplo es la evaluación del impacto visual de actuaciones urbanísticas que a continuación se presenta. Previa descripción y medición de la calidad y fragilidad visual del paisaje, se evalúa el impacto visual de una actuación urbanística prevista en el litoral andaluz.

\section{Metodología de valoración de la calidad visual.}

\subsection{Componentes y visibilidad. Calidad visual intrínseca.}

La percepción de la realidad circundante se efectúa en un $87 \%$ a través del sentido de la vista. Los componentes físicos y bióticos del paisaje pueden desagregarse en cuatro; tierra, agua, vegetación y estructuras artificiales, diferenciados por sus características visuales básicas. La primera a considerar es su accesibilidad al observador casual, por lo que habrá que distinguir las vistas de gran incidencia de aquellas que requieren un desplazamiento específico para su apreciación. El trazado de cuencas visuales desde los puntos emisores de vistas de interés limita el análisis a las áreas efectivamente visibles desde los puntos seleccionados tras el trabajo de campo.

Una vez ponderada su accesibilidad, la calidad visual de los paisajes seleccionados consiste en tres parámetros (Escribano et al., 1987):

a) Calidad visual intrínseca, atractivo visual de cada punto por su morfología, hidrología, vegetación, ...

b) Calidad visual del entorno inmediato, definido por un radio de 700 metros, donde se distinguen los elementos visualmente atractivos.

c) Calidad del fondo escénico, definido por su intervisibilidad (amplitud de la cuenca visual), altitud, vegetación, hidrología, singularidades geológicas o constructivas. 
Fernández Enríquez, A., Arcila Garrido, M., García Sanabria, J. (2019): "Metodología de valoración de impacto visual. Aplicación en la playa de el Palmar de Vejer (Cádiz).", GeoFocus (Artículos), no 23, p. 141-162. ISSN: 15785157 http://dx.doi.org/10.21138/GF.624

\subsection{Elementos de análisis visual.}

Las propiedades visuales de los elementos del medio y sus composiciones constituyen la expresión plástica del paisaje. Los sonidos y olores son también atributos importantes y cualifican la estructura básica de la percepción, que puede establecerse sustancialmente a partir de las cualidades visuales objetivas; forma, línea, color, textura, escala y movimiento (Escribano et al., 1987).

a) Forma: volumen o superficie de objetos unificados en su emplazamiento, tales como geomorfología, vegetación o láminas de agua. Se caracteriza por su geometría, complejidad y orientación respecto al plano dominante del paisaje, y es determinante en la precepción del color. El movimiento incrementa su incidencia, ya que el ojo humano lo percibe a mayor distancia que los objetos inmóviles.

b) Línea: franja de contraste brusco entre elementos (color, forma, textura). Se caracteriza por su fuerza, complejidad y orientación respecto a los ejes dominantes. La fuerza descansa en la intensidad, continuidad y unicidad de su trazo. La complejidad se define por la variedad de direcciones que sigue, y el contraste resulta de la composición de diversas líneas, dando dominancia a las divergentes del eje principal sobre las que se amoldan a este. Destaca el carácter focalizador de la línea, que guía la vista del observador.

c) Color: es la principal propiedad visual de una superficie, y determina en gran medida sus cualidades estéticas. En igualdad de los elementos visuales, destacan los colores cálidos, claros y brillantes sobre los fríos, oscuros y mates.

d) Textura: agregación indiferenciada de formas o colores que se perciben como variaciones o irregularidades en una superficie continua. Se caracteriza por su grano (tamaño relativo de las irregularidades superficiales), densidad, regularidad y contraste interno. Las texturas de grano grueso y elevado contraste interno tienden a dominar sobre las de grano fino poco contrastadas.

e) Escala; es la relación existente entre el tamaño de un objeto y el entorno donde se sitúa. El observador compara los objetos con referencias de dimensiones conocidas, destacando la apreciación de volúmenes pesados y compactos en espacios cerrados sobre la de objetos pequeños y ligeros en espacios amplios.

f) Movimiento; es cualidad fundamental del paisaje, aunque no es aprehensible mediante fotografía, pero debe reseñarse pues introduce variabilidad en caso de movimientos lentos (nubes, mareas), y atrae la atención en caso de ser pausado (fauna), focalizando totalmente la percepción, incluso a mayor distancia que objetos inmóviles, en caso de movimientos rápidos (penachos de humo, tráfico viario, molinos de viento).

\subsection{Procedimiento y criterios de análisis visual.}

a) Selección de panorámicas.

En primera instancia se efectúa un reconocimiento fotográfico del terreno y se contrasta con la fotointerpretación de los usos del suelo y la topografía, trazando con el modelo digital de elevaciones las cuencas visuales existentes para seleccionar vistas representativas de estas.

b) Trazado de esquemas visuales e identificación de componentes.

Sobre estas vistas se dibujan los esquemas visuales, que simplifican la realidad observada agrupando sus componentes en diez categorías, a las que corresponde un coeficiente de ponderación de su calidad visual. Su signo se atribuye en función del grado de discordancia o integración visual del elemento. 
Fernández Enríquez, A., Arcila Garrido, M., García Sanabria, J. (2019): "Metodología de valoración de impacto visual. Aplicación en la playa de el Palmar de Vejer (Cádiz).", GeoFocus (Artículos), no 23, p. 141-162. ISSN: 15785157 http://dx.doi.org/10.21138/GF.624

- + /-1 Industria e infraestructuras.

- $+/-2$ Urbano.

- $+/-3 \quad$ Agropecuario.

- $\quad+-4 \quad$ Natural degradado.

- +/-5 Hitos e impactos, naturales o antrópicos.

c) Matriz de valoración de elementos.

Se continúa efectuando la valoración formal de cada elemento estimando y homogeneizando las cualidades visuales objetivas según los siguientes parámetros para tres categorías de análisis; morfología, vegetación y edificación.

- Forma, compuesto por la suma de integridad, complejidad y orientación, valorados de 1 a 3 y divididas por tres.

- Línea, compuesto por la suma de intensidad, complejidad y contraste valorados de 1 a 3 y divididas por tres.

- Color, compuesto por la suma de intensidad, variabilidad y contraste, valorados de 1 a 3 y divididas por tres.

- Textura, compuesto por la suma de grano, densidad, regularidad y contraste interno valorados de 1 a 3 y divididas por cuatro.

- Escala, compuesta únicamente por el valor de contraste, valorado de uno a tres.

d) Matriz de valoración; ponderación

El resultado de la valoración se pondera dos veces, primero en función de su incidencia visual; fondo escénico, entorno cercano (entre 500 y 1.500 metros del punto de observación) y paisaje inmediato; y segundo, por el grado de accesibilidad para el observador casual, diaria (desde núcleos urbanos y vías de comunicación) frecuente (desde lugares de veraneo y ocio, o vías secundarias), o esporádica (asequible con desplazamiento específico).

e) Normalización de valores

La suma de los valores ponderados de los factores componentes nos da la calidad intrínseca del elemento analizado, que se expresa en un rango comprendido entre $-100 \%$ (impacto máximo) y $100 \%$ (hito visual). Obtenemos la calidad absoluta del elemento, que reducida a escala porcentual se presenta de 1 a $100 \%$, con signo positivo o negativo.

\subsection{Fragilidad visual.}

La fragilidad visual se define como la susceptibilidad al cambio del paisaje al desarrollar un uso sobre él. Su opuesto es la capacidad de absorción visual, aptitud de absorción visual de modificaciones o alteraciones sin merma de la calidad. La calidad es intrínseca, mientras la capacidad está en función del cambio de uso.

Para cuantificar la fragilidad visual se estiman tres grupos de factores:

- Factores biofísicos.

- Suelo y cubierta vegetal; densidad, altura, estratificación, estacionalidad y contrastes cromáticos, entre la vegetación y de esta con el suelo.

- Pendiente, que favorece la absorción visual en las cotas más bajas.

- Orientación. La pendiente puede ocultar totalmente los impactos. En general hay menos fragilidad en las zonas donde el observador se encuentra a contraluz. Las vistas al Norte se hacen con el sol detrás, pero con peor iluminación que las vistas al sur, a contraluz. La puesta de sol se considera más asequible al observador casual que la amanecida. 
Fernández Enríquez, A., Arcila Garrido, M., García Sanabria, J. (2019): "Metodología de valoración de impacto visual. Aplicación en la playa de el Palmar de Vejer (Cádiz).”, GeoFocus (Artículos), no 23, p. 141-162. ISSN: 15785157 http://dx.doi.org/10.21138/GF.624

- Factores morfológicos.

- Tamaño de la cuenca visual.

- Compacidad de la cuenca.

- Elongación de la cuenca.

- Altura relativa del punto respecto a la cuenca.

- Factores histórico-culturales.

- Existencia o proximidad a puntos singulares, estimados por su unicidad, valor tradicional e interés histórico.

- Accesibilidad de la observación desde carreteras y núcleos habitados.

La integración de la fragilidad visual del punto y del entorno define la fragilidad visual intrínseca, que junto a la accesibilidad proporciona la fragilidad visual adquirida, elemento de referencia para la planificación.

3.5. Caracterización del valor social y económico del paisaje.

Se ha de categorizar los espacios para aproximarnos a su relevancia en el contexto social y económico. A tal efecto se propone la siguiente escala:

- Paisajes degradados; vertederos, canteras, industria contaminante, usos desordenados...

- Paisajes vulgares; fruto de la producción estandarizada de espacios urbanos.

- Escenarios con potencial representativo; los lugares preservados de la degradación visual son cada vez más escasos. Aun careciendo de valores destacados, muchos parajes reúnen requisitos para convertirse en atractivos, destacando en este sentido las posibilidades de la campiña.

- Productos paisajísticos; la inversión en estética crea lugares a preservar, tales como espacios urbanos, determinadas obras públicas, lugares de ocio y esparcimiento...

- Hitos y señas de identidad local; son los clásicos motivos retratados, las vistas más destacadas de cada lugar.

4. Aplicación al plan parcial de ordenación "Malcucaña". Vejer de la Frontera (Cádiz).

4.1 Introducción.

El Catálogo del Plan Especial de Protección del Medio Físico de la Provincia de Cádiz, redactado en 1986 y publicado en 2007 (JUNTA DE ANDALUACÍA, 2007) incluía el complejo litoral de interés ambiental "El Palmar" y el contiguo espacio de protección cautelar "Llanos del Palmar". Estos espacios protegidos por la ley han adolecido de protección efectiva frente a lo que el propio Plan señalaba en 1986; "esta zona está empezando a verse amenazada por las construcciones unifamiliares dispersas y sin ordenación a pie de playa".

El Palmar es hoy uno de los más clamorosos casos de parcelación y edificación ilegal en Andalucía ${ }^{4}$. Estas viviendas ilegales se encuentran en proceso de regularización mediante un PERI (Plan Especial de Reforma Interior) sobre 40 hectáreas con 260 propietarios, y la urbanización del SAU-5 (Suelo Apto para Urbanizar) con 63 hectáreas y unas 800 viviendas irregulares. Es junto a ésta aglomeración de viviendas en proceso de regularización donde Riera Marsá planteó en 2001 un proyecto denominado El Palmar Gran Resort, situado entre la

\footnotetext{
${ }^{4}$ Diario de Cádiz titulaba el 26/07/2016: "Las esposas de dos policías de Vejer levantan casas ilegales en El Palmar". Disponible en: http://www.diariodecadiz.es/article/provincia/2335760/las/esposas/dos/policias/vejer/levantan/casas/ilegal es/palmar.html
} 
Fernández Enríquez, A., Arcila Garrido, M., García Sanabria, J. (2019): "Metodología de valoración de impacto visual. Aplicación en la playa de el Palmar de Vejer (Cádiz).”, GeoFocus (Artículos), nº 23, p. 141-162. ISSN: 15785157 http://dx.doi.org/10.21138/GF.624

edificación ilegal y el arroyo Conilete, sinuoso límite de los términos municipales de Vejer y Conil. Aprobado por la Junta de Andalucía desde 2007, tras la retirada en 2009 del promotor original pasó a sus acreedores, el Grupo Tarje y Caja Madrid, y a Bankia a principios de 2011.

La aprobación definitiva del Plan Parcial de Malcucaña fue publicada en el BOP de Cádiz $\mathrm{N}^{\mathrm{o}} 174$ de 10 de septiembre de 2010. Con una superficie de $272.448 \mathrm{~m}^{2}$, prevé la construcción y puesta en funcionamiento de 2 hoteles de 4-5 estrellas con un total de 727 habitaciones, con dotación de Espacios Libres para usos deportivos al aire libre en Zona de Policía del Dominio Público. Hidráulico (DPH) y en Zona de Servidumbre del Dominio Público Marítimo Terrestre (DPMT).

Actualmente la propiedad la detenta la SAREB, con un plazo de 15 años para devolver al mercado esta parcela, previsiblemente a precio de saldo y siempre que supere la oposición de la plataforma Salvar El Palmar, que desde finales de 2009 ha recogido 62.000 firmas contra el proyecto 5 .

A pesar de la degradación del entorno por la proliferación de viviendas ilegales, la actuación incide sobre un memorable hito visual, el conjunto formado por la playa y los llanos de El Palmar. Se trata de una seña de identidad local que adquiere aún mayor dimensión por la escasez a nivel regional y nacional de espacios con tal calidad y atractivo turístico.

\subsection{Selección de panorámicas.}

La percepción se efectúa en dos ejes fundamentales, NNW-SSE y SSW-NNE. En el primer eje destacan las vistas obtenidas desde el casco urbano de Conil, sobre los llanos de El Palmar con el área de actuación al fondo, su vista inversa sobre el casco de Conil, y las obtenidas desde la carretera de El Palmar circulando en ambos sentidos.

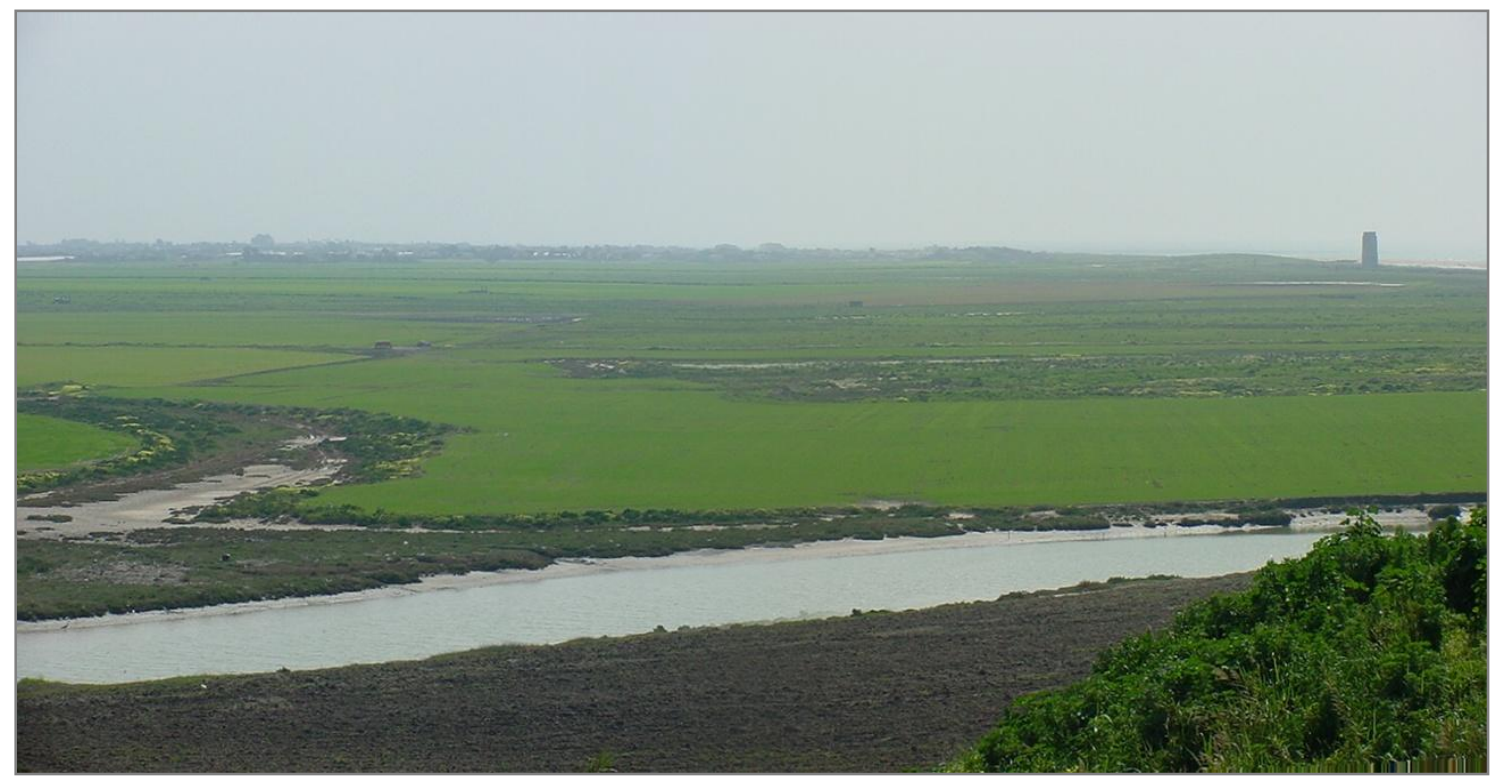

Figura 1. Vista desde Conil.

Fte. Fotografía: IBERMAD S.L.

\footnotetext{
${ }^{5}$ El diario.es: La playa de El Palmar: de botín urbanístico a activo tóxico. Disponible en: http://www.eldiario.es/andalucia/Palmar-botin-urbanistico-activo-toxico_0_125638386.html
} 
Fernández Enríquez, A., Arcila Garrido, M., García Sanabria, J. (2019): "Metodología de valoración de impacto visual. Aplicación en la playa de el Palmar de Vejer (Cádiz).", GeoFocus (Artículos), no 23, p. 141-162. ISSN: 15785157 http://dx.doi.org/10.21138/GF.624

La vista inversa, hacia Conil, será la disfrutada desde el área de actuación, que tan sólo limitará la visibilidad que hay ahora desde el carril de acceso al área de actuación y a la playa, por lo que en este sentido la incidencia es pequeña. Por tanto, se analizará la vista obtenida desde Conil, con una salvedad a destacar; las relaciones de escala entre los elementos componentes no serán consideradas en la magnitud plasmada en la vista, puesto que esta vista es sensiblemente similar a las obtenidas desde la carretera conforme nos acercamos al área de actuación. Considerando la escala variable se pueden englobar estas vistas cercanas en la general, lo que permite analizar la incidencia independientemente del punto de observación que se adopte en el eje NNW-SSE.

En el segundo eje, SSW-NNE, en el que las vistas obtenidas desde la carretera hacia la playa se verán afectadas por un apantallamiento de 100 metros, prolongación del que ejerce la urbanización de El Palmar, destacan las vistas que se disfrutan desde la playa, en las proximidades de la Torre de Castilobo, desde donde se disfruta una muy amplia panorámica de este litoral en óptimo grado de conservación, así como del entorno y el relieve cercano, destacando la ausencia de impactos antrópicos relevantes, en especial parques eólicos. El único deterioro visual perceptible es el de la urbanización colindante, ligada al espacio balneario.

\subsection{Trazado de esquemas visuales e identificación de componentes}

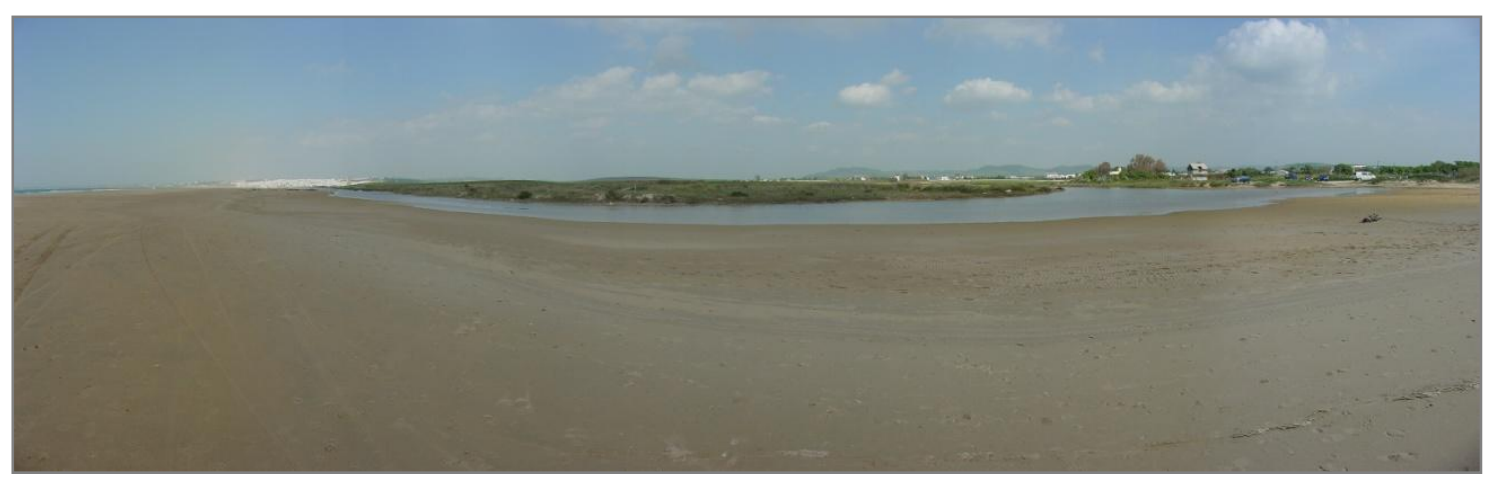

Figura 2. Vista desde la playa de Castilobo. Fte. Fotografía: IBERMAD S.L.

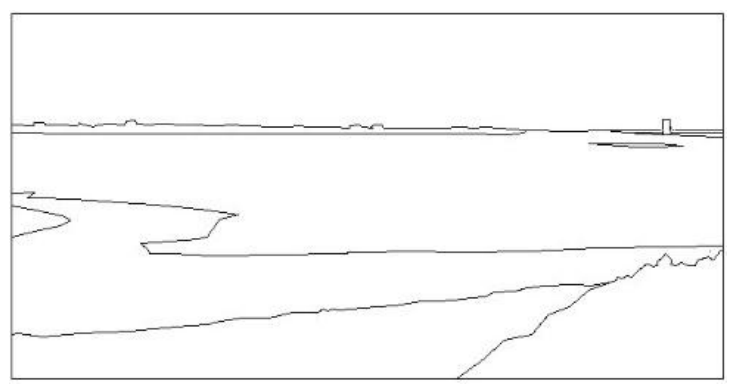

Figura 3. Elementos integrados (inertes, bióticos y antrópicos) visibles desde Conil. Fte. IBERMAD S.L.

Los elementos visibles desde el casco urbano de Conil (Figura 3) pueden agruparse en:

- Elementos inertes; Llanos de El Palmar, Arroyo Salado, Playa de Castilobo, Océano Atlántico y bóveda celeste. 
Fernández Enríquez, A., Arcila Garrido, M., García Sanabria, J. (2019): "Metodología de valoración de impacto visual. Aplicación en la playa de el Palmar de Vejer (Cádiz).", GeoFocus (Artículos), no 23, p. 141-162. ISSN: 15785157 http://dx.doi.org/10.21138/GF.624

- Elementos bióticos; arbolado del talud de Conil.

- Elementos antrópicos; torre de Castilobo y asentamiento de El Palmar.

Los elementos visibles desde la playa de Castilobo pueden agruparse en:

- Elementos inertes; Cauce del Arroyo Conilete, Playa de Castilobo, relieves circundantes, Océano Atlántico y bóveda celeste.

- Elementos bióticos: llanura mareal, con pastizal salino, marismas y formaciones dunares.

- Elementos antrópicos; casco urbano de Conil y asentamiento de El Palmar.

\subsection{Matriz de evaluación de la calidad visual preoperacional}

De la panorámica, obtenida desde el casco urbano de Conil, se obtuvo la matriz de evaluación de la calidad visual de la panorámica $\mathrm{n}^{\mathrm{0}}$ 1-preoperacional (anexo).

La calidad visual del paisaje analizado es de 78,90\%. En este resumen se omite su completa descripción pormenorizada por la excesiva extensión, pero a modo de ejemplo de la valoración se presentan las consideraciones consignadas en la matriz para el primer elemento desglosado, los Llanos (de El Palmar); se trata de un elemento territorial percibido como agropecuario, en el entorno inmediato y de accesibilidad diaria desde el núcleo de Conil y la CA-9028. Presenta una forma simple, orientada a favor del plano dominante, el horizontal, con líneas simples pero intensas y contrastadas, cromatismo intenso, estacionalmente variable y contrastado con los elementos contiguos, textura de grano fino, denso, regular y con escaso contraste interno, con escala de apreciación masiva y sin movimiento perceptible.

De la panorámica obtenida desde la playa de Castilobo se obtuvo la segunda matriz (anexo).

La calidad visual del paisaje analizado es de $77,04 \%$. No es posible incluir aquí todas las valoraciones detalladas, pero se ha justificado exhaustivamente para cada elemento. Por ejemplo, para la Llanura mareal se ha justificado así en el estudio completo: pastizal salino, con marismas y formaciones dunares, que constituye un hito inmediato de accesibilidad frecuente, diaria en época estival. El contacto con el Conilete incrementa la incidencia visual de la orientación de este volumen, simple en configuración y complejo en contenido. Su línea y color son intensos, complejos, variables y contrastados, y su textura es de grano grueso, denso, regular y con marcados contrastes internos. La escala de apreciación es media y carece de movimiento salvo el de la fauna y la vegetación adaptada al viento.

\subsection{Fragilidad visual.}

El área de actuación se encuentra dentro de una cuenca amplia, dominada desde el núcleo de Conil, dentro de la cual se encuentra una cuenca más restringida de forma alargada, dominada a su vez por la carretera CA-9028. Dada la estrechez de esta carretera, que impide distraer la atención, el punto de fuga y por tanto el flujo visual es paralelo a la carretera. Caso de ampliarse, el trazado rectilíneo permitiría ampliar el campo visual, observando la playa y los llanos con mayor comodidad. En su configuración actual, el flujo visual se dirige directamente al área de actuación al circular hacia el Sur.

En cuanto a los factores biofísicos, la ausencia de vegetación, la orientación perpendicular a la carretera con pendientes hacia el Conilete y la topografía predominantemente llana, lejos de disminuir la incidencia del área de actuación, incrementan la visibilidad de la zona, inserta en un paraje litoral excepcional en el que se cuenta con un hito histórico y visual, 
Fernández Enríquez, A., Arcila Garrido, M., García Sanabria, J. (2019): "Metodología de valoración de impacto visual. Aplicación en la playa de el Palmar de Vejer (Cádiz).", GeoFocus (Artículos), no 23, p. 141-162. ISSN: 15785157 http://dx.doi.org/10.21138/GF.624

la Torre de Castilobo.

En detalle se aprecia que el área de actuación se recorta contra el fondo del asentamiento de El Palmar. La topografía de la plataforma litoral va elevándose ligeramente desde la vega del Conilete hacia Barbate. Las viviendas unifamiliares, que se acumulan hacia la playa, y la vegetación arbustiva configuran una pantalla de altura ligeramente inferior a la decena de metros y que va a servir de fondo escénico a la actuación.

Por todo ello, la fragilidad visual del área de actuación es muy elevada. La capacidad de absorción visual ante la actuación propuesta es muy baja, por lo que esta deberá contar con medidas correctoras. Hay que destacar que esta situación ya se da en la urbanización existente, que ha producido una merma de la calidad visual escasamente compensada por setos que actúan como pantallas. Por tanto, la actuación es una oportunidad de corregir impactos existentes, lo que disminuye el valor absoluto del impacto visual previsible.

\subsection{Cuantificación de la incidencia visual.}

Para dimensionar la ocupación de cuenca visual implícita a la actuación se considera la posición de esta respecto al punto de observación seleccionado. Dado que la percepción visual humana se efectúa en un campo de $180^{\circ}$, que el paisaje inmediato es el percibido hasta una distancia de 500 metros, el entorno próximo abarca hasta 1.500 metros, límite de apreciación nítida, y que los elementos situados más allá están en el fondo escénico, se calcula para cada caso la longitud del perímetro de esta semicircunferencia (multiplicando 3,1416 por la distancia exacta para un elemento o agrupándolas en las categorías descritas).

La actuación se encuentra a pie de carretera, a 2750 metros del casco urbano de Conil y a 100 metros de la playa de El Palmar. Ocupa un 5,9\% de los 8.639 metros lineales de horizonte del semicírculo definido por el radio de 2.750 metros, situándose en el centro de esta subcuenca observada desde Conil.

Respecto a la subcuenca observada desde la playa de El Palmar, la actuación tiene una disposición oblicua, con frente a la playa en torno a 400 metros. Adoptando una profundidad de campo de 500 metros, el semicírculo visible a esa distancia es de 570 metros, respecto a los cuales la actuación supone un $25,46 \%$ situado cerca del centro geométrico de la subcuenca.

\section{Resultados}

\subsection{Descripción de la actuación prevista en la playa de El Palmar y su incidencia visual}

La actuación implica ocupar los pastizales existentes entre el asentamiento diseminado de El Palmar y el arroyo Conilete, avanzando la línea edificada sobre los llanos de El Palmar.

Respecto a la primera de las vistas se superpone al asentamiento existente, siendo poco perceptible el avance de la edificación. La altura final es de bajo +2 plantas, que deberán elevarse dos metros sobre el nivel del mar, por lo que la altura final es de 16 metros más el metro que se sube de cota en la vega del Conilete. 
Fernández Enríquez, A., Arcila Garrido, M., García Sanabria, J. (2019): "Metodología de valoración de impacto visual. Aplicación en la playa de el Palmar de Vejer (Cádiz).”, GeoFocus (Artículos), nº 23, p. 141-162. ISSN: 15785157 http://dx.doi.org/10.21138/GF.624

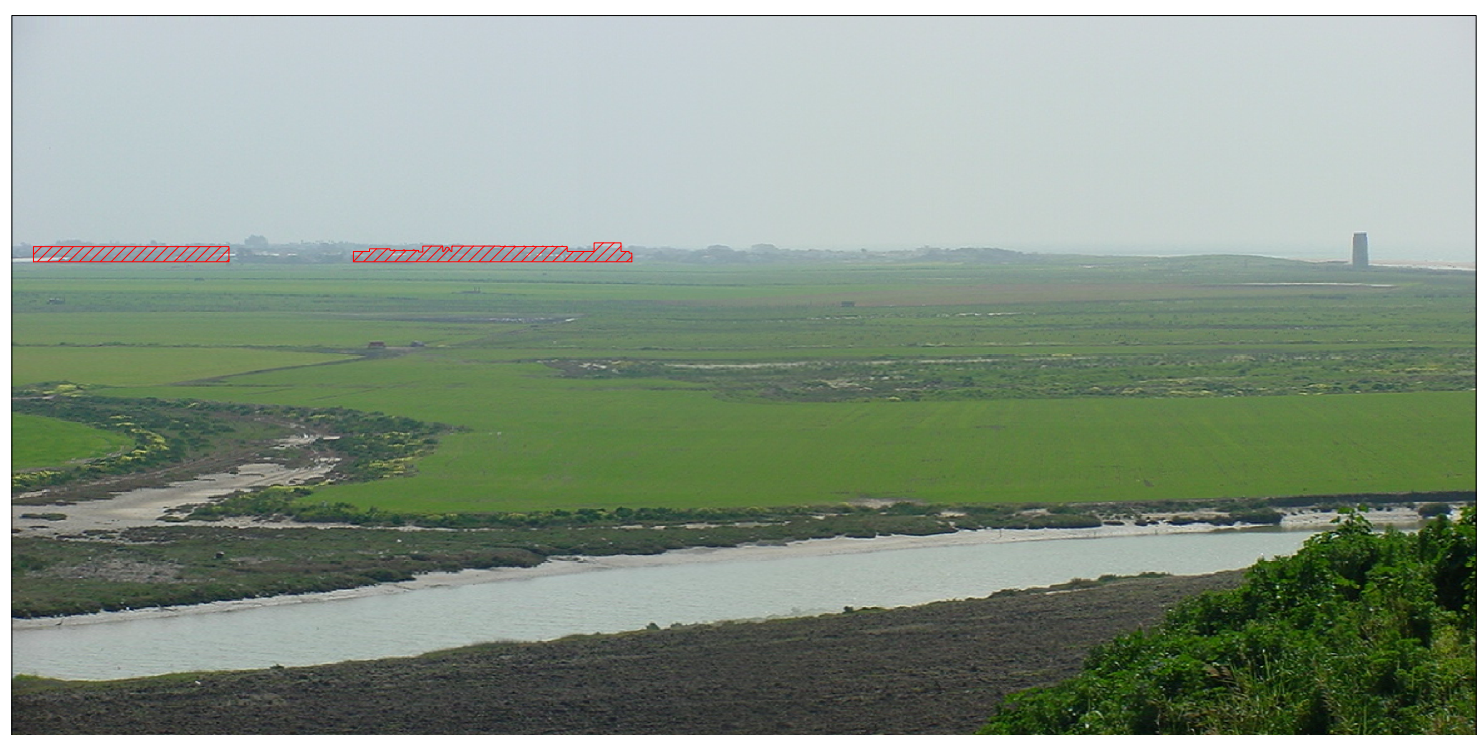

Figura 5. Simulación de la vista postoperacional desde Conil. Fte. IBERMAD S.L.

La calidad visual ha descendido de 78,9\% a 76,87\%. El asentamiento de El Palmar incrementa su impacto, pues su volumen se hace más macizo y complejo, su línea y color son más intensos, variables, complejos y contrastados, su gruesa textura es más densa y regular, tiene elevado contraste interno y el contraste de escala es mayor

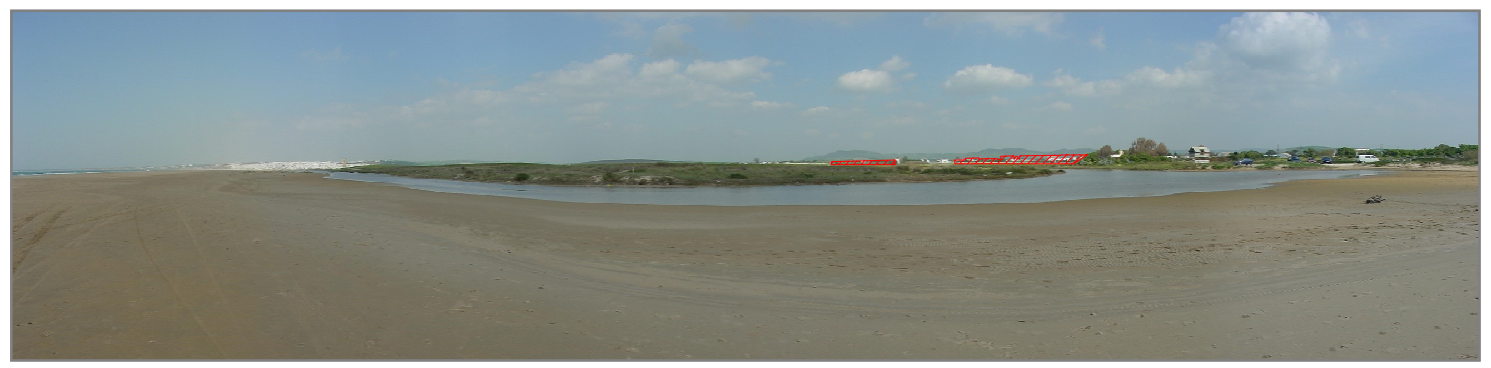

Figura 6. Simulación de la vista postoperacional desde la playa de Castilobo.

Fte. IBERMAD S.L.

Respecto a la segunda vista considerada, la actuación supone un avance de la urbanización en dirección a Conil sobre el fondo escénico de los relieves cercanos, desnaturalizando en buena medida el paisaje de la marisma y el Conilete, que en sí mismo permanece intacto.

La calidad visual ha descendido de $77,04 \%$ a $76,51 \%$. Este descenso es imputable al mayor impacto del asentamiento de El Palmar, que avanza entre la marisma, el Conilete y los relieves del fondo escénico, y será especialmente destacado durante la noche, cuando el alumbrado preste apariencia urbana a este paraje natural.

\subsection{Medidas correctoras.}

De ambos análisis se desprende que la calidad visual desciende en todas las perspectivas, que lo hace en magnitudes sensibles, y que la fragilidad visual y el valor social y 
Fernández Enríquez, A., Arcila Garrido, M., García Sanabria, J. (2019): "Metodología de valoración de impacto visual. Aplicación en la playa de el Palmar de Vejer (Cádiz).", GeoFocus (Artículos), nº 23, p. 141-162. ISSN: 15785157 http://dx.doi.org/10.21138/GF.624

económico de este paisaje son muy elevados. Deben aplicarse medidas correctoras, imprescindibles para una integración plausible de los usos propuestos sin deterioro de las condiciones visuales, principal soporte de los usos turísticos objeto de la actuación.

El impacto visual final ha de ser positivo, y esto ha de verificarse sometiendo a evaluación la efectiva implantación de las medidas correctoras contempladas en el estudio de impacto ambiental, que son las siguientes:

\subsubsection{Relativas al diseño de los edificios.}

El diseño de los edificios deberá estar acorde con la tipología edificatoria propia de la zona, evitando la introducción de elementos discordantes y estableciendo medidas para minimizar su impacto paisajístico. El techado de los edificios ha de dar lugar a una línea irregular. Se recomienda que no se mantengan líneas de altura continuas de más de 100 metros. Se recomienda el uso de cubiertas que generen líneas no ortogonales.

El color de los exteriores y, sobre todo, la vegetación ha de ayudar a romper la continuidad de los volúmenes y del perfil. Para ello se plantarán especie arbóreas -autóctonas, siempre que sea posible- de manera que sus copas oculten y difuminen las líneas ortogonales de la edificación. Algunas de dichas copas deben quedar asimismo por encima de la línea de techo y ha de plantarse vegetación arbustiva que oculte, en determinados tramos, el nivel de base de la edificación.

En el tratamiento de exteriores se minimizarán las superficies reflectantes. La edificación debe integrar pocos colores, recomendándose el blanco y los colores del entorno, especialmente los ocres.

\subsubsection{Relativas a la vegetación y la jardinería de la actuación.}

Tratamiento vegetal de los bordes de la actuación, mediante tapiz de arbustos en el talud del Conilete, cuya ribera merece una restauración de sus condiciones naturalísticas, mejorándose, además, a largo plazo las condiciones de estabilidad del talud.

Selección de arbolado autóctono, recomendándose evitar las pantallas vegetales opacas. Un arbolado de hoja perenne permite la visibilidad desde la zona hotelera hacia los llanos y Conil, y elimina los perfiles superiores de la edificación. Los árboles de hoja caduca son más adecuados para zonas de estancia, pues dan sombra en verano y no quitan el sol en invierno, y los perennes enmascaran mejor durante todo el año los discordantes perfiles geométricos.

\subsubsection{Relativas a la iluminación.}

El alumbrado debe ajustarse estrictamente al mínimo, utilizando lámparas con cubierta y báculos del menor tamaño posible, especialmente en el borde exterior de la actuación y los espacios libres.

\section{Discusión.}

El procedimiento de Evaluación de Impacto Ambiental es la herramienta que permite a la administración andaluza ejercer control sobre los cambios en el paisaje, control ampliado a la sociedad durante el periodo de información pública previo a su aprobación. Este procedimiento hace necesaria la intervención de expertos en la fase de redacción de los Estudios de Impacto 
Fernández Enríquez, A., Arcila Garrido, M., García Sanabria, J. (2019): "Metodología de valoración de impacto visual. Aplicación en la playa de el Palmar de Vejer (Cádiz).”, GeoFocus (Artículos), nº 23, p. 141-162. ISSN: 15785157 http://dx.doi.org/10.21138/GF.624

Ambiental, sin perjuicio de una eventual aplicación del método de las preferencias del público durante su exposición pública.

La metodología presentada cuantifica la calidad y fragilidad visual del entorno y el impacto paisajístico del proyecto utilizando exclusivamente parámetros objetivos de larga tradición y utilidad contrastada en estudios de paisaje (forma, línea, color, textura, escala, movimiento, distancia, posición del observador...), actualmente en uso por diversas agencias federales norteamericanas. Estos parámetros han sido incorporados hace tiempo a la literatura paisajista en español (Escribano et al., 1987), sin implementarse hasta ahora su aplicación con innovaciones metodológicas como la que aquí se propone.

La utilidad de este novedoso método reside en su carácter objetivo, que permite verificar cada paso del proceso, pues las eventuales desviaciones en la matriz de valoración son detectadas con facilidad. La adopción de las medidas correctoras ha de reiterarse hasta que el impacto visual sea positivo, pues la calidad visual es el objetivo irrenunciable de la arquitectura del paisaje, especialmente en entornos como el litoral andaluz, donde los paisajes naturales de calidad se insertan entre sectores muy urbanizados.

Para preservar los enclaves con calidad visual es necesario contar con herramientas como la propuesta, que permite a los promotores ajustar el proyecto a los objetivos de calidad visual de la administración, a los técnicos de la administración evaluar dicho ajuste, y a todos los interesados presentar alegaciones, incluyendo en su caso las medidas correctoras necesarias para realimentar el proceso hasta que el resultado final sea acorde a la escala social de valores.

Entre sus ventajas, además de las citadas cabe añadir la escalabilidad. El procedimiento puede iterarse las veces que sea necesario para incluir cuantas vistas y factores perceptivos como se estimen convenientes. Entre las desventajas del procedimiento, su carácter riguroso, pormenorizado y exhaustivo hace necesaria su utilización por personal cualificado. En cuanto a su supervisión, puede ser facilitada en gran medida presentando las matrices en formato digital para experimentar el ajuste de las diferentes valoraciones de cada parámetro.

\section{Conclusiones}

La protección del paisaje ha precedido a la protección ambiental, pero su incorporación a la toma de decisiones en planificación urbanística y territorial se había limitado a prestar utilidad como síntesis socio-ambiental a través de "unidades de paisaje". Más recientemente, el Convenio Europeo del Paisaje promueve un inventario sistemático de los paisajes y el establecimiento de objetivos de calidad con cobertura integral del territorio, enfoque que hemos denominado vertical. Se han desarrollado recientemente buen número de metodologías con vocación de dar cobertura integral al territorio o aplicarse en determinados ámbitos o sectores de actividad.

Las determinaciones paisajísticas procedentes del enfoque vertical se integran con facilidad como una fuente más de información sectorial en la planificación urbanística y territorial. En la fase previa a la toma de decisiones, el acopio de información relevante no puede omitir la calidad paisajística del territorio. Esta aportación del paisaje no previene el principal problema en ordenación del territorio, que es la desconexión entre las fases de planificación y gestión y los consiguientes desajustes entre objetivos y resultados.

Complementariamente, el enfoque horizontal propio de la fotografía paisajística es óptimo para integrar a escala humana los diversos elementos perceptibles en el entorno inmediato de un lugar, emulando el método vector-factor de estudio de la difusión de los 
Fernández Enríquez, A., Arcila Garrido, M., García Sanabria, J. (2019): "Metodología de valoración de impacto visual. Aplicación en la playa de el Palmar de Vejer (Cádiz).", GeoFocus (Artículos), no 23, p. 141-162. ISSN: 15785157 http://dx.doi.org/10.21138/GF.624

impactos ambientales producidos por proyectos concretos, la conocida como matriz de Leopold.

El paisaje está llamado a ser la eficiente herramienta de gobernanza territorial (Zoido, 2012) que conecte objetivos y resultados en un ejercicio de democracia cultural y paisajística propugnado por el Consejo de Europa para materializar la ciudadanía europea (CONSEJO DE europa, 2000).

Para ello es preciso integrar cuidadosamente los aspectos objetivos y subjetivos del paisaje, ampliamente tratados por filosofía, arquitectura paisajística, ingeniería, psicología, biología y planificación territorial (Cañas y Otero, 1993). El paisaje ha sido minusvalorado, a pesar de la riqueza conceptual del término. Mientras el territorio ha sido exhaustivamente regulado, el paisaje ha sido calificado en el pasado como concepto ambiguo, polisémico o endeble, estéril debate ya superado (Santos y Ganges, 2003; Zoido, 2012).

El enfoque horizontal permite valorar el paisaje como un recurso natural más en evaluación de impacto ambiental, pero no sólo eso; también es vehículo privilegiado de participación pública, como lugar de encuentro interdisciplinar y herramienta de construcción de consenso social, tanto considerándolo integrador de los valores ambientales del territorio, como considerándolo en su carácter estrictamente perceptivo, pues la percepción del territorio por la población es predominantemente visual.

Actualmente disponemos de legislación del más alto rango que insta a planificar el paisaje y a implementar herramientas de gestión. En cumplimiento del Convenio Europeo del Paisaje se ha de identificar y caracterizar los paisajes de la totalidad del territorio, y realizar el seguimiento de sus transformaciones (art. 6.C).

En entornos homogéneos, naturales o agrícolas, es relativamente sencillo limitar las transformaciones del paisaje midiendo su contraste con el paisaje precedente. De ahí se obtiene el grado de ajuste con los objetivos de calidad paisajística. Esto es más difícil en entornos periurbanos, sobre todo del litoral, donde la desordenada proliferación de edificaciones hace necesario herramientas muy precisas para afinar la protección y mejora del paisaje.

A tal efecto, la metodología propuesta, de carácter horizontal, cuantifica minuciosamente las características visuales del paisaje antes y después del proyecto, permitiendo prever al detalle su impacto visual y las medidas correctoras necesarias. Se trata por tanto de una herramienta de contraste entre los criterios de la administración y los de los promotores de transformaciones paisajísticas. Partiendo de la situación actual, se establece una valoración cuantitativa que garantiza un lenguaje común, objetivo y transparente en el control de las transformaciones paisajísticas y su adecuación a los objetivos sociales de calidad. 
Revista Internacional de Ciencia y Tecnología de la Información Geográfica International Review of Geographical Information Science and Technology

Fernández Enríquez, A., Arcila Garrido, M., García Sanabria, J. (2019): "Metodología de valoración de impacto visual. Aplicación en la playa de el Palmar de Vejer (Cádiz).”, GeoFocus (Artículos), no 23, p. 141-162. ISSN: 15785157 http://dx.doi.org/10.21138/GF.624

\section{Anexo: Matrices de valoración de la calidad visual}

Tabla 1. Matriz de evaluación de la calidad visual de la vista desde Conil preoperacional.

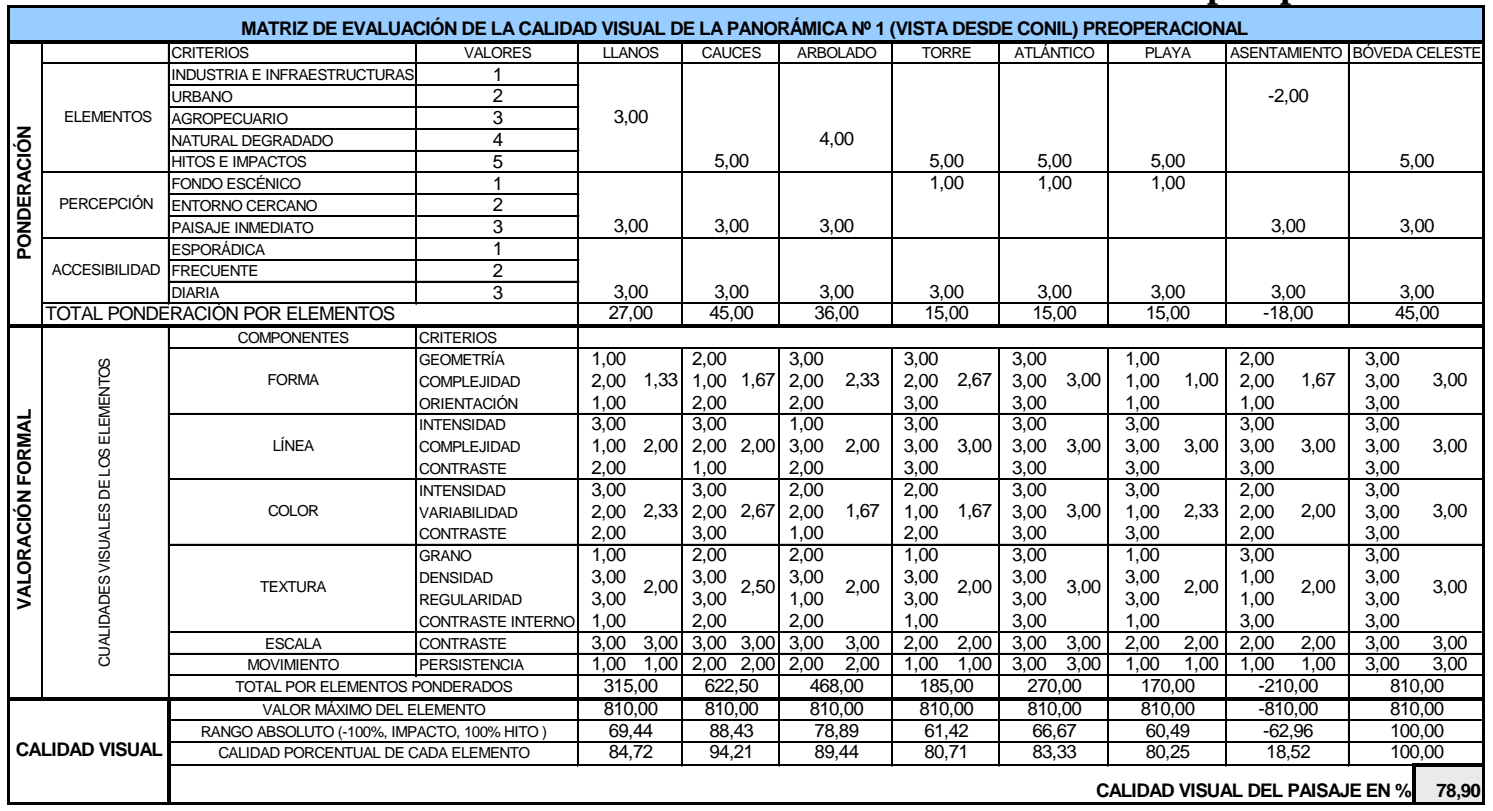

Fte. IBERMAD S.L.

Tabla 2. Matriz de evaluación de calidad visual de vista desde la playa de Castilobo preoperacional.

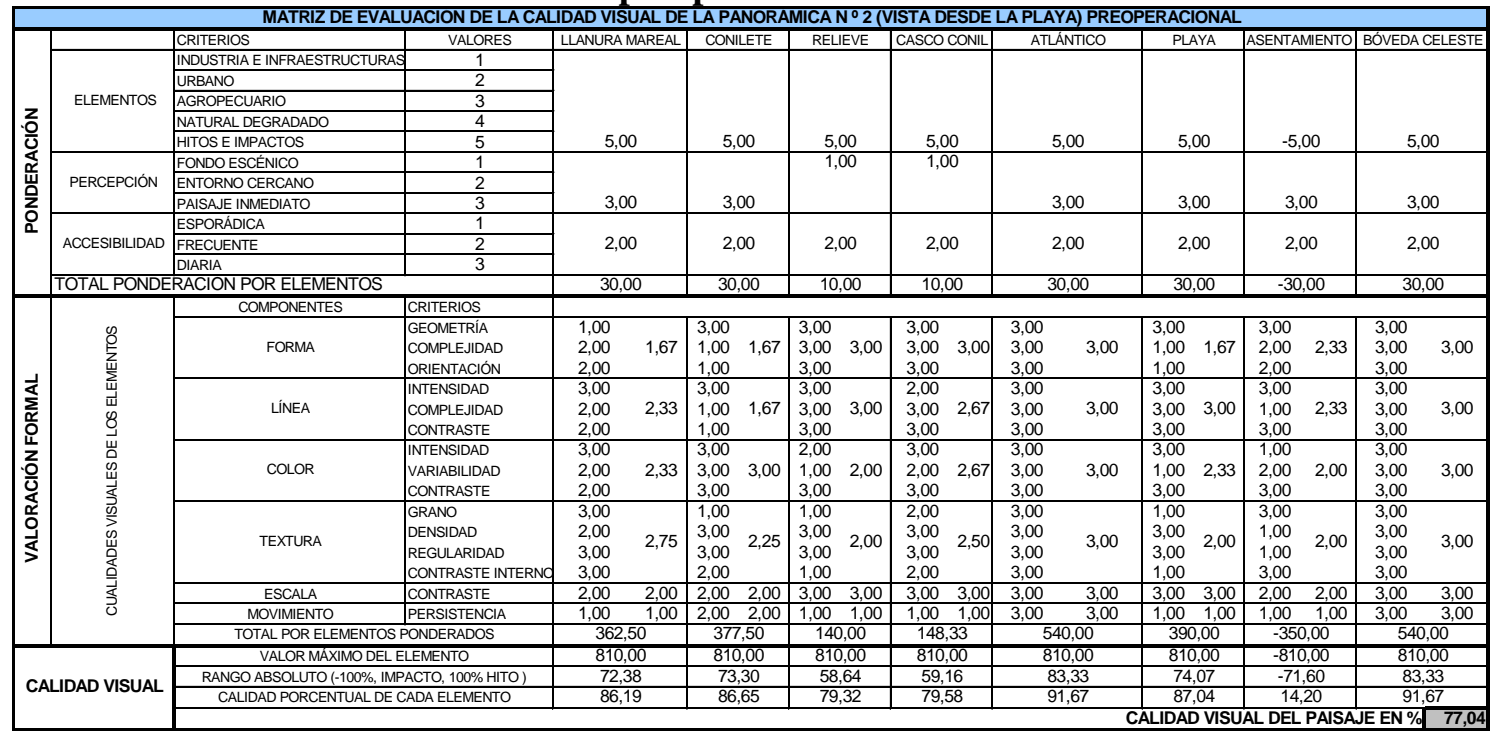

Fte. IBERMAD S.L. 
Revista Internacional de Ciencia y Tecnología de la Información Geográfica International Review of Geographical Information Science and Technology

Fernández Enríquez, A., Arcila Garrido, M., García Sanabria, J. (2019): "Metodología de valoración de impacto visual. Aplicación en la playa de el Palmar de Vejer (Cádiz).”, GeoFocus (Artículos), no 23, p. 141-162. ISSN: 15785157 http://dx.doi.org/10.21138/GF.624

Tabla 3. Matriz de evaluación post-operacional y resumen de la vista desde Conil.

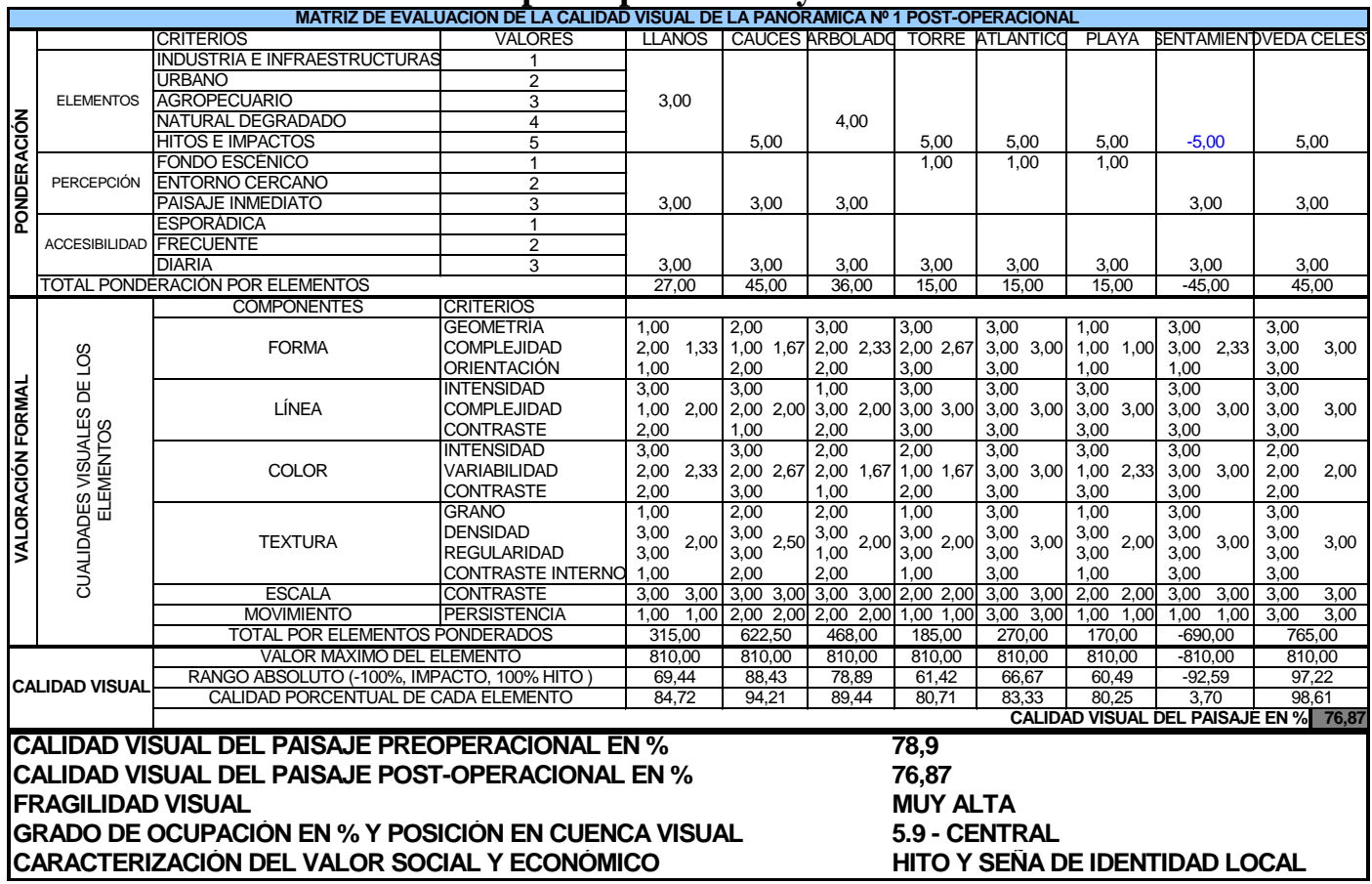

Fte. IBERMAD S.L.

Tabla 4. Matriz de evaluación post-operacional y resumen de la vista desde Castilobo.

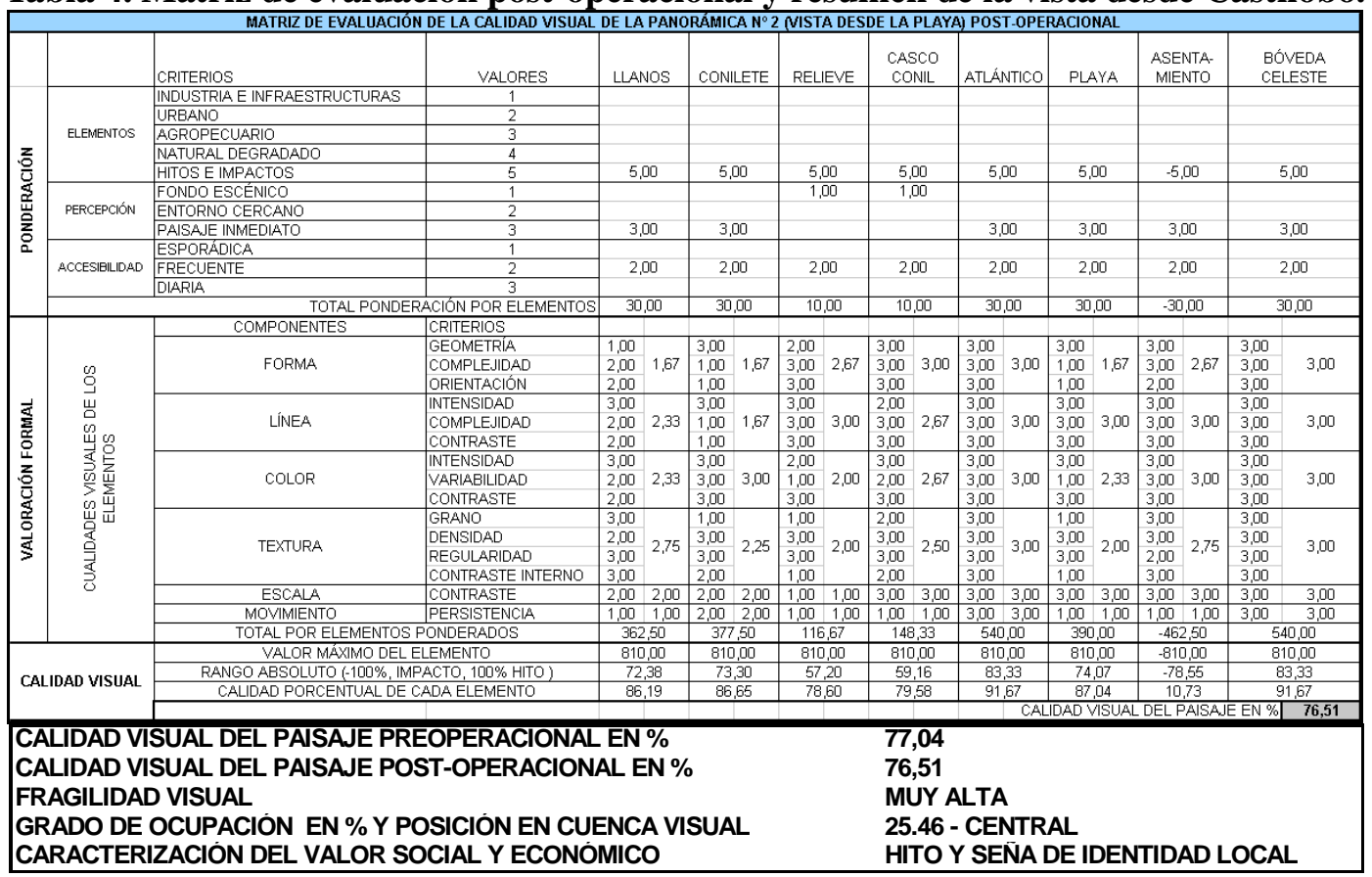

Fte. IBERMAD S.L. 
Fernández Enríquez, A., Arcila Garrido, M., García Sanabria, J. (2019): "Metodología de valoración de impacto visual. Aplicación en la playa de el Palmar de Vejer (Cádiz).”, GeoFocus (Artículos), no 23, p. 141-162. ISSN: 15785157 http://dx.doi.org/10.21138/GF.624

\section{Bibliografía}

Arriaza, M., Cañas-Ortega, J.F., Cañas-Madueño, J.A. y Ruiz-Aviles, P. (2004). “Assessing the visual quality of rural landscapes". Landscape and Urban Planning $\mathrm{n}^{\circ} 69,115-125$.

Arthur, L.M., Daniel, T.C. y Boster, R.S. (1977). “Scenic assessment: an overview”. Landscape Planning n 4 $^{\circ}$ 109-129.

Borobio Sanchiz, M. (dir.) (2012). Guía de Estudios de Impacto e Integración Paisajística. Xunta de Galicia. Consellería de Medio Ambiente, Territorio e Infraestructuras, Santiago de Compostela.

Busquets I Fàbregas, J. y Muñoz Ramírez, F. (dirs.) (2010). Guia d'estudis d'impacte $i$ integració paisatgística. Generalitat de Catalunya, Departament de Política Territorial i Obres Públiques. Barcelona.

Campos Cánovas, A. y López Sánchez, M. (2006). “Análisis, tratamiento y problemática del paisaje urbano y natural de los conjuntos históricos. El caso de la Comunidad Autónoma de Murcia (España)". Scripta Nova Vol. X, núm. 218 (90).

Cañas G. y Otero Pastor, I. (1993). "Diversas posturas ante el paisaje". Cuadernos de ordenación del territorio, segunda época año II, n 5 , 13-18.

Churchward, C., Palmer J.F., Nassauer, J.I. y Swanwick, C.A (2013). National Cooperative Highway Research Program Report 741; Evaluation of Methodologies for Visual Impact Assessments. Transportation Research Board, Washington, D.C.

Consejo de Europa (2000). Conferencia europea de ministros responsables de ordenación del territorio (CEMAT). Principios directores para el desarrollo territorial sostenible del continente europeo. [En línea]. Ministerio de Medio Ambiente, Madrid. <https://rm.coe.int/1680700174> [16/03/2019].

Cloquell-Ballester, V.A., Torres-Sibille, A.C., Cloquell-Ballester, V.A., y Santamarina-Siurana M.C. (2012). "Human alteration of the rural landscape: Variations in visual perception". Environmental Impact Assessment Review n ${ }^{\circ}$ 32, 50-60.

Escribano, M.M., De Frutos, M., Iglesias, E., Mataix C., y Torrecillas, I. (1987). El paisaje. Cátedra de planificación y proyectos, ETSI Montes. Unidades Temáticas Ambientales de la DGMA. MOPU. Madrid.

Estévez, R., Prieto, F., y Alfonso, C. (2016). Costa 16. Cambios de ocupación del suelo en la costa de España, 1987-2011. [En línea]. Observatorio de la sostenibilidad. <www.observatoriosostenibilidad.com> [16/03/2019].

García, L., Hernández, J., y Ayuga, F. (2003). "Analysis of the exterior color of agroindustrial buildings: a computer aided approach to landscape integration". Journal of Environmental Management 69 (2003) 93-104.

García, L., Hernández, J., y Ayuga, F. (2006). "Analysis of the materials and exterior texture of agro-industrial buildings: a photo-analytical approach to landscape integration". Landscape and Urban Planning 74 (2006) 110-124.

García-Moruno, L., Montero-Parejo, M. J., Hernández-Blanco, J. y López-Casares, S. (2010). "Analysis of lines and forms in buildings to rural landscape integration". Spanish Journal of Agricultural Research 2010 8(3), 833-847.

Hurtado, J.P., Fernández, J., Parrondo, J.L. y Blanco, E. (2004). "Spanish method of visual 
Fernández Enríquez, A., Arcila Garrido, M., García Sanabria, J. (2019): "Metodología de valoración de impacto visual. Aplicación en la playa de el Palmar de Vejer (Cádiz).", GeoFocus (Artículos), nº 23, p. 141-162. ISSN: 15785157 http://dx.doi.org/10.21138/GF.624

impact evaluation in wind farms". Renewable and Sustainable Energy Reviews 2004, n 8, 48391.

Jeong, J. S., García-Moruno, L. y Hernández-Blanco, J. (2014). “Un modelo web para la asistencia en la toma de decisiones en la integración de las construcciones rurales mediante planificación espacial multi-criterio". Informes de la Construcción, Vol. 66, 533.

Jeong, J. S. y García-Moruno, L. (2016). "The study of building integration into the surrounding rurallandscape: Focus on implementation of a Web-based MC-SDSS and its validation by twoway participation". Land Use Policy 57 (2016) 719-729.

Junta de Andalucía (2007). Resolución de 14 de febrero de 2007, de la Dirección General de Urbanismo, por la que se dispone la publicación del Plan Especial de Protección del Medio Físico y Catálogo de Espacios y Bienes Protegidos de la provincia de Cádiz. Sevilla, Boletín Oficial de la Junta de Andalucía núm. 57, 21/03/2007. Consejería de Obras Públicas y Transportes.

Junta de Andalucía (2012). Acuerdo de 6 de marzo de 2012, del Consejo de Gobierno, por el que se aprueba la Estrategia de Paisaje de Andalucía. Boletín Oficial de la Junta de Andalucía número 62 de 29/03/2012, Sevilla, Consejería de La Presidencia, Junta de Andalucía.

Laurie, M. (1983). Introducción a la arquitectura del paisaje. Gustavo Gili. Barcelona.

Leopold, L.B. (1969). Quantitative comparison of some aesthetic factors among rivers. Geological Survey circular 620. US Department of the Interior. Washington D.C.

Leopold, L.B., Clarke, F.E., Hanshaw, B.B., y Balsley, J.R. (1971). A procedure for evaluating environmental impact. Washington, D.C., U.S. Geological Survey.

Litton, R. B. (1968). Forest Landscape Description and Inventories - a basis for land planning and design. USDA Forest Service. Berkeley, California.

Manchado, C., Gómez-Jauregui, V. y Otero, C. (2015). "A review on the Spanish Method of visual impact assessment of wind farms: SPM2". Renewable and Sustainable Energy Reviews 2015. nº49, 756-767.

Muñoz Criado, A. (dir.) (2012). Guía metodológica. Estudios de paisaje. Conselleria de Infraestructuras, Territorio y Medio Ambiente, Generalitat valenciana, Valencia.

Otero Pastor, I., Casermeiro Martínez, M.A., Ezquerra Canalejoa, A. y Esparcia Mariño, P. (2007). "Landscape evaluation: Comparison of evaluation methods in a region of Spain". Journal of environmental management $\mathrm{n}^{\circ}$ 85, 204-214.

Palmer, J.F. (2004). "Using spatial metrics to predict scenic perception in a changing landscape". Landscape and Urban Planning n 69, 201-218.

Ruiz Sánchez, M. A., Pascual Castaño, C., Velarde Catolfi-Salvoni, M. D., Martínez De Anguita, P., Cruz, F. y Flores, P. (2006). "Valoración cuantitativa de la calidad visual del paisaje agro-forestal mediante herramientas SIG". En Camacho, M.T., Cañete, J.A. y Lara Valle, J.J. eds. (2006): El acceso a la información espacial y las nuevas tecnologías geográficas, pp. 1223-1231. Editorial Universidad de Granada, Granada.

Santos y Ganges, L. (2003). "Las nociones de paisaje y sus implicaciones en la ordenación". Ciudades, $\mathrm{n}^{\circ}$ 7, 2002-2003, págs. 41-68.

Schroeder, H.W. (1988). "Visual Impact of Hillside Development: Comparison of Measurements Derived from Aerial and Ground-Level Photographs". Landscape and Urban 
Fernández Enríquez, A., Arcila Garrido, M., García Sanabria, J. (2019): "Metodología de valoración de impacto visual. Aplicación en la playa de el Palmar de Vejer (Cádiz).”, GeoFocus (Artículos), no 23, p. 141-162. ISSN: 15785157 http://dx.doi.org/10.21138/GF.624

Planning. No $15,119-126$.

Shafer, E.L., Hamilton, J.E. y Schmidt, E.A. (1969). "Natural Landscape Preferences: A Predictive Model". Journal of Leisure Research 1.1 (Winter 1969): 197.

Torres Sibille, A.C. (2010). Visual Impact Assessment of Human Interventions on the Landscape: The case of Wind Farms and Solar Power Plants. Tesis doctoral no publicada. Valencia. [En línea]. Universitat Politècnica de València. Valencia. <http://hdl.handle.net/10251/9147> [16/03/2019].

Zoido, F. (2012). "El paisaje un concepto útil para relacionar estética, ética y política". Scripta Nova vol. XVI, $\mathrm{n}^{\mathrm{o}}$ 407. [En línea]. Universidad de Barcelona. Barcelona. <http://www.ub.es/geocrit/sn/sn-407.htm> [16/03/2019].

Zube, E.H., Sell, J.L., y Taylor, J.G. (1982). "Landscape perception: research, application and theory". Landscape Planning ${ }^{\circ}$ 9, 1-3.

Zubelzu, S. y Hernández, A. (2015). "Método de valoración de paisajes forestales basado en el uso de atributos estéticos como variables explicativas de las preferencias". Madera y Bosques vol. $21, \mathrm{n}^{\mathrm{o}} 1,45-62$. 